Hedonic Value of Transit Accessibility: An Empirical Analysis in a Small Urban Area Author(s): Xinyu Cao and Jill A. Hough

Source: Journal of the Transportation Research Forum, Vol. 47, No. 3 (Public Transit Special Issue 2008), pp. 171-183

Published by: Transportation Research Forum

Stable URL: http://www.trforum.org/journal

The Transportation Research Forum, founded in 1958, is an independent, nonprofit organization of transportation professionals who conduct, use, and benefit from research. Its purpose is to provide an impartial meeting ground for carriers, shippers, government officials, consultants, university researchers, suppliers, and others seeking exchange of information and ideas related to both passenger and freight transportation. More information on the Transportation Research Forum can be found on the Web at www.trforum.org. 


\title{
Hedonic Value of Transit Accessibility: An Empirical Analysis in a Small Urban Area
}

\author{
by Xinyu Cao and Jill A. Hough
}

Many programs of the SAFETEA-LU have pointed to improving transit services and individuals' accessibility in small urban areas. Urban economic theory suggests that improving accessibility by investing in transportation has the potential to drive up bids for land. However, will the improved transit accessibility in small urban areas increase property values? A number of studies have investigated the impact of rail transit on home sales but produced mixed results. Further, few studies have explored how transit influences the lease rate of apartments. This question is more relevant because transit accessibility tends to have a greater impact on apartment dwellers than home owners. Using about 400 apartment dwellers in Fargo, North Dakota, this study developed a hedonic price model to determine implicit price of proximity to bus routes. We found a negative impact of bus transit on apartment rent after controlling for other factors, however. We speculated that in a small urban area, this negative relationship could be mainly attributable to spurious relationships from other causal factors, as well as nuisance effects of bus transit itself.

\section{INTRODUCTION}

Transportation systems provide travel options for people to move among spatially-segregated activities such as working, shopping, and entertainment. Therefore, transportation investments that ease movement from one location to another presumably have important impacts on the achievement of social objectives such as reducing congestion and improving the environment (Giuliano 2004; Wegener and Fürst 1999). How the enhanced accessibility affects land value is also important because transit investments are often justified by promoting economic development (e.g. Mackett and Edwards 1998).

The American Public Transportation Association states that "Across the country, dial-a-ride, bus, rail and commuter rail services are providing enhanced travel options and expanding access, often in dramatic ways. Better access means rising market value for adjacent properties and buildings" (APTA undated, p.2). According to urban economics, the relative increase in accessibility provided by transit facilities may increase property value because the larger demand for high-accessible locations drives up the bid for lands in those locations (Mills and Hamilton 1994). However, previous studies provide mixed results on how transit infrastructure influences property value. First, some studies found that proximity to rail transit has a positive impact on residential property value (Gatzlaff and Smith 1993; Haider and Miller 2000; Lewis-Workman and Brod 1997; Voith 1991). However, it is known the enhanced accessibility itself is not sufficient to stimulate urban development and increase property value; the positive impact of accessibility greatly depends on other factors such as economic situations, land use policies, and development subsidies (Cervero 1996; Gatzlaff and Smith 1993; Giuliano 2004). On the other hand, transit infrastructure may bring about nuisance effects due to noise and crime. For example, Nelson (1992) found that proximity to transit stations is positively associated with property value in lower-income neighborhoods but has a negative influence on property value in higher-income neighborhoods although both neighborhoods were served by the same rail transit. This suggests that nuisance effects of the rail transit exceed its accessibility effects in higher-income neighborhoods. Chen et al. (1998) found that property values decrease and then increase as the distance to transit stations increases, an interaction of a positive accessibility effect and a negative nuisance effect. 
These studies intensively focused on the impact of rail transit (including heavy rail, light rail, and commuter rail) on home sales. We should also pay attention to the relationship between bus transit and values of rental properties. Although rail transit represents a huge investment, bus transit has a much larger network in the region and carries the majority of transit passengers (Pucher 2004). In other words, the impact of rail transit on property value tends to be limited to the local corridor, while the influence of bus transit is likely to be regional due to its extensive network. Therefore, its influence on property value merits investigation. Generally, transit attracts patrons from people living in the urban core, transit-captives, and some choice users. Therefore, transit investments tend to have a limited impact on individuals' accessibility compared to highway investments. Given that many apartment dwellers are transportation-disadvantaged people, transit access and the level of service may have a larger impact on apartment dwellers than home owners. Further, apartment dwellers tend to value the importance of transportation factors in their residential choices, compared to home owners (Bina et al. 2006a, 2006b; Cao 2007). Therefore, transit infrastructure is more likely to affect lease rates than home prices.

Several studies have pointed to bus transit and/or rent value. Using real estate sales data collected a few years before and after introducing a new bus system in Denver in 1971, Koutsopoulos (1977) found that single-family houses close to bus routes tend to have higher values than those away from the bus system. Bina et al. (2006b) also found the number of bus stops per square mile is positively associated with home prices. Further, Benjamin and Sirmans (1996) showed that proximity to rail stations positively affects the lease rate of apartments in Washington, DC. Cervero (1996) revealed that the distance to BART stations has a negative impact on apartment rent in some neighborhoods but has no influence in other examined neighborhoods in the San Francisco Bay Area. Bina et al. (2006a) is one of few studies investigating the influence of bus transit on lease rates. They found the density of bus stops is negatively associated with apartment rents in Austin, TX. They speculated that noise of buses and the spread of bus services in lower-income neighborhoods may contribute to this negative association. The opposite impacts of the bus system on sale prices and lease rates may also arise from different sampling methods used in these two studies (Bina et al., 2006a; 2006b): choice-based sample vs. random sample. Bina et al. (2006a) pointed out the drawback of a choicebased sampling method and highly recommended a random sampling approach.

The SAFETEA-LU authorized \$52.6 billion for transit investments over six years. Many programs (such as New Freedom) have pointed to providing funding for transit in small urban areas with a population less than 200,000. These programs are expected to improve the mobility and accessibility of people in small urban areas. Urban economic theory suggests that improving accessibility by investing in transportation has the potential to drive up bids for land. However, will the improved transit accessibility in small urban areas add value to adjacent properties? The purpose of this study is to explore the influence of transit facilities on the lease rate of apartments using the data randomly collected from apartment dwellers in Fargo, ND. This study is distinct because it uses the data from a small urban area and is one of few studies regarding the relationship between bus transit accessibility and apartment rent. The next section briefly reviews the hedonic price model. Section 3 describes the data and variables. Section 4 presents the results of correlation analysis and the hedonic model. The final section discusses the underlying reasons for the model results.

\section{HEDONIC PRICE MODEL}

The hedonic price model is commonly used to determine the impact of transportation investments on property value. The model assumes that goods are characterized as a package of inherent attributes, and the observed prices of goods reflect the utility (or implicit prices) of these attributes (Rosen 1974). Therefore, the value of a residence is the summation of implicit prices for the characteristics associated with the residence. What constitutes the characteristics of a residential property? Previous research pointed to location, structure, and neighborhood attributes (e.g., Chin and Chau 2003; Lewis-Workman and Brod 1997). Some of these attributes are summarized in Table 1. 
Table 1: Influential Attributes of Property Value

\begin{tabular}{|c|c|}
\hline Category & Attributes \\
\hline Location & $\begin{array}{l}\text { Distance to the central business district } \\
\text { Distance to the nearest station of transit } \\
\text { Level of services of transportation } \\
\text { Aesthetic or obstructed view } \\
\text { Geomancy } \\
\ldots\end{array}$ \\
\hline Structure & $\begin{array}{l}\text { The number of rooms including bedroom and bathroom } \\
\text { Floor area } \\
\text { Age of the building } \\
\text { Quality of the building } \\
\text { The existence of a basement, garage, patio, etc. } \\
\text { Appliances (e.g., kitchen equipment) and amenities (e.g., swimming pool) } \\
\ldots\end{array}$ \\
\hline Neighborhood & $\begin{array}{l}\text { Social class of neighborhood } \\
\text { Schools, hospitals, and places of worship } \\
\text { Crime rate } \\
\text { Noise } \\
\text { Proximity to commercial districts } \\
\ldots\end{array}$ \\
\hline
\end{tabular}

Source: Chin and Chau (2003)

In mathematical form, the hedonic function of an apartment can be expressed as:

(1) $Y=f(L, S, N)$,

where Y stands for the dependent variable: rent of an apartment; L, S, and N denote location, structural, and neighborhood characteristics of the apartment, respectively. The partial derivative of the function with respect to an attribute represents the marginal implicit price (shadow price) of that attribute. For a linear regression model, the coefficient of an attribute is the shadow price of that attribute.

\section{DATA AND VARIABLES}

The data used in this study came from a self-administered telephone survey conducted in Fargo, ND. Fargo, located in the Red River Valley region, is a typical small city in the Midwest (Figure 1). The land area is about 30 square miles and the population was 90,599 at the 2000 Census. The FargoMoorhead metropolitan area had a population of 174,347 in 2000. Fargo is a major transportation hub for the surrounding regions: two interstate highways (I29 and I94) run across the city (Figure 2). Inside the metropolitan area, the Metro Area Transit (MAT, http://www matbus.com) operates 18 routes to provide transit services for three adjacent cities: Fargo, West Fargo, and Moorhead. In 2006, Fargo MAT provided about 900,000 one-way passenger trips.

Survey questions were developed from questionnaires used in previous research projects by the first author and Dr. Kara Kockelman. The survey was pre-tested on students and staff of North Dakota State University. Participants were asked to first complete the survey, then to discuss the survey questions with the researchers in one-on-one interviews. Based on these pretests, survey questions were modified and refined.

We purchased a database of apartment dwellers from AccuData America (http://www.accudata. com/). In May and June 2007 our contract interviewer from the National Agriculture Statistics 


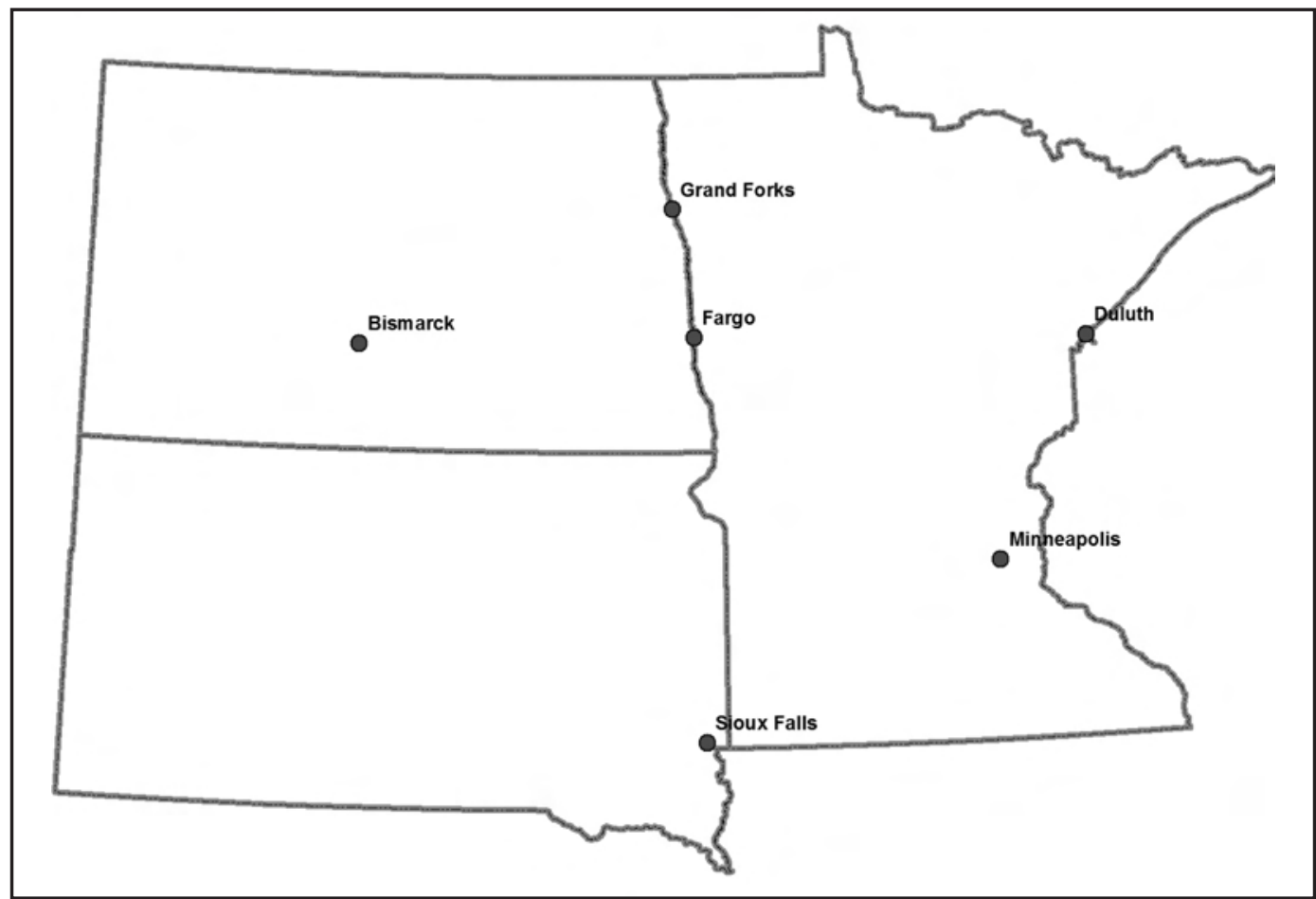

Service called respondents randomly selected from the database. Since those who do not answer the phone may substantially differ from those answering the phone, we adopted a callback procedure. As an incentive to complete the survey, respondents were told they would be entered into a drawing to receive one of five $\$ 50$ cash prizes. Ultimately, among 1,395 individuals who answered the phone, 415 did not live in an apartment any more. The number of responses totaled 424, equivalent to a $43.2 \%$ response rate based on the valid respondents only. As shown by the dots in Figure 2, most of the respondents were gathered in several locations, which reflect the cluster of apartment buildings. Note that 26 respondents were removed from the analysis because they either live in senior centers or subsidized apartments and the nominal rent they reported does not reflect the true value of properties.

In the survey, respondents were asked to report their monthly rent (the total rent if they share an apartment). Moreover, a series of questions asked attributes of the apartment (e.g., number of bedrooms and bathrooms as listed in Table 2). These attributes serve as control variables. As shown later in Table 3, we also asked respondents to indicate how true 20 attributes are for their current apartments and neighborhoods on a four-point ordinal scale from "Not at all true" (1) to "Entirely true" (4). The characteristics as perceived by respondents reflect fundamental differences in attributes of residential environments. 
Figure 2: Residential Locations of Respondents and Transit Routes

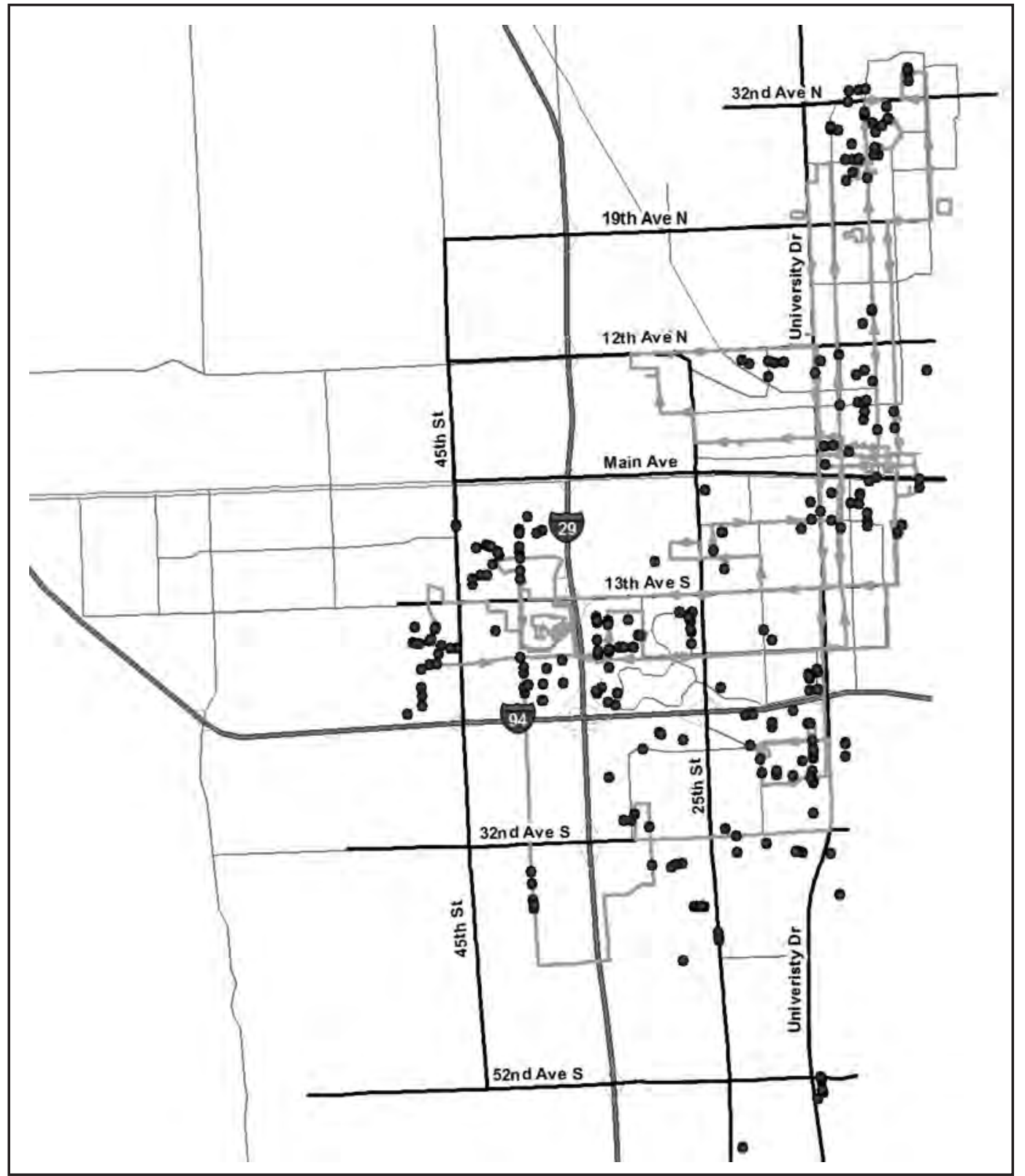

Note: The dots are observations and the lines with arrows are bus routes.

A detailed route map is available at http://www.matbus.com/Documents/FargoBusRoutes.pdf. 


\begin{tabular}{|c|c|c|c|c|c|}
\hline & $\mathbf{N}$ & Minimum & Maximum & Mean & $\begin{array}{c}\text { Std. } \\
\text { Deviation }\end{array}$ \\
\hline \multicolumn{6}{|l|}{ Apartment attributes } \\
\hline Monthly rent & 379 & 265 & 1140 & 604.26 & 174.04 \\
\hline \# bedrooms & 398 & 1 & 3 & 1.96 & 0.58 \\
\hline \# bathrooms & 398 & 1 & 2.5 & 1.17 & 0.26 \\
\hline With a patio, balcony, deck or porch & 398 & 0 & 1 & 0.73 & 0.44 \\
\hline Living in the garden level & 397 & 0 & 1 & 0.21 & 0.41 \\
\hline Controlled access & 397 & 0 & 1 & 0.82 & 0.39 \\
\hline Furnished apartment & 398 & 0 & 1 & 0.01 & 0.10 \\
\hline Garage cost included in the rent & 398 & 0 & 1 & 0.74 & 0.44 \\
\hline Apartment size & 207 & 250 & 2000 & 986.76 & 249.93 \\
\hline \multicolumn{6}{|l|}{ Appliances provided in the apartment } \\
\hline Refrigerator & 398 & 0 & 1 & 1.00 & 0.05 \\
\hline Stove & 398 & 0 & 1 & 0.99 & 0.10 \\
\hline Microwave & 398 & 0 & 1 & 0.29 & 0.45 \\
\hline Dishwasher & 398 & 0 & 1 & 0.82 & 0.38 \\
\hline Washer/dryer & 398 & 0 & 1 & 0.20 & 0.40 \\
\hline \multicolumn{6}{|l|}{ Utilities paid by dwellers } \\
\hline Electricity & 398 & 0 & 1 & 0.86 & 0.35 \\
\hline Snow removal & 398 & 0 & 1 & 0.01 & 0.09 \\
\hline Heat & 398 & 0 & 1 & 0.20 & 0.40 \\
\hline Water & 398 & 0 & 1 & 0.04 & 0.20 \\
\hline Sewer/garbage & 398 & 0 & 1 & 0.04 & 0.20 \\
\hline \multicolumn{6}{|l|}{ Amenities offered by apartment complex } \\
\hline Clubhouse/community room & 398 & 0 & 1 & 0.24 & 0.43 \\
\hline Swimming pool & 398 & 0 & 1 & 0.14 & 0.35 \\
\hline Landscaped garden & 398 & 0 & 1 & 0.09 & 0.29 \\
\hline Fitness or sport facilities & 398 & 0 & 1 & 0.24 & 0.43 \\
\hline Playground & 398 & 0 & 1 & 0.09 & 0.29 \\
\hline Free cable TV/internet & 398 & 0 & 1 & 0.07 & 0.25 \\
\hline \multicolumn{6}{|l|}{ Land use characteristics } \\
\hline Accessibility & 395 & 545.54 & 1209.78 & 957.28 & 172.00 \\
\hline Population density & 395 & 0 & 21929.67 & 6117.33 & 4319.66 \\
\hline Employment density & 395 & 0 & 24768 & 3061.07 & 4769.24 \\
\hline Retail employment density & 395 & 0 & 5513.70 & 722.90 & 1226.03 \\
\hline Service employment density & 395 & 0 & 19139.92 & 1787.76 & 3409.39 \\
\hline Travel time to the CBD & 395 & 1.69 & 16.98 & 9.35 & 3.27 \\
\hline Living $w /$ in $1 / 8$ mile of transit routes & 395 & 0 & 1 & 0.56 & 0.50 \\
\hline Living w/in $1 / 4$ mile of transit routes & 395 & 0 & 1 & 0.80 & 0.40 \\
\hline Living $w /$ in $1 / 2$ mile of transit routes & 395 & 0 & 1 & 0.92 & 0.27 \\
\hline
\end{tabular}

Note: if a variable ranges from 0 to 1 , it is a dummy variable. 
Following the survey, we calculated several land use characteristics at the TAZ (traffic analysis zone) level. Using the data from regional travel demand forecasting model, we first computed a few density measurements and vehicular travel time to the central business district (CBD) as shown in Table 2. Further, regional accessibility was computed using the following gravity-based measure:

(2) $A_{i}=\sum_{j} O_{j} f\left(t_{i j}\right)=\sum_{j} O_{j}\left(a \times t_{i j}{ }^{b} \times e^{c \times t_{i j}}\right)$,

where $A_{i}$ is the accessibility of TAZ(i); $O_{j}$ is the number of jobs in TAZ(j); $f\left(t_{i j}\right)$ is the friction function to travel between TAZ(i) and TAZ(j). Here, we adopted the HBW (home-based work) Gamma function coefficients for friction factors where $\mathrm{a}=28507, \mathrm{~b}=-0.020$, and $\mathrm{c}=-0.123$. Using GIS, three dummy variables were created to indicate whether a respondent lived within $1 / 8,1 / 4$, or 1/2 mile (network distance) of transit routes, respectively. In Fargo, although there are designated bus stops, the MAT bus would stop at a shelter location or any corner as long as it is safe traffic-wise. Therefore, the distance to the transit route is actually the network distance to the bus stop.

\section{RESULTS}

We first examined the correlations of the monthly rent with objective land use characteristics at the TAZ level. As shown in Table 3, most of these characteristics are significantly associated with the rent, except the three measurements of employment density. These associations revealed that apartments located in high-accessible, dense areas tend to have a lower rent than those in the areas with a low level of accessibility and density; the rent of apartments tends to increase as vehicular travel time to CBD increases. Generally, these associations seem to be counterintuitive due to the commonly-believed premium for high accessibility. On the other hand, these associations may represent spurious relationships. For example, accessibility may act as a proxy for such attributes as space: the farther an apartment is from the CBD, the more spacious it is, and the more expensive. Apartments within specific distances (1/8, 1/4, 1/2 mile, respectively) of bus routes tend to have a lower rent than those away from transit facilities; and the closer apartments are to bus routes, the stronger the association is. Therefore, it seems that proximity to bus routes has a negative impact on apartment rent.

In addition, the lease rate is significantly correlated with various perceived measures of the apartment and neighborhood (Table 3). In general, the findings are consistent with our expectations. Note the age of the apartment (relatively new living unit) has the largest correlation with the rent. Easy access to interstate highway has a positive association with the rent but easy access to public transit is negatively associated with the rent. Thus, the influence of both objective and perceived measures of public transit pointed to a negative impact of bus transit on the lease rate of apartments.

The ordinary least squares (OLS) technique was used to determine hedonic value of transit accessibility, controlling for other factors. Potential explanatory variables were entered into the model in groups, starting with apartment attributes reported by respondents, followed by objective land use characteristics measured at the TAZ level, then characteristics of the current apartment and neighborhood perceived by respondents. At each step, insignificant variables were dropped, and the model was re-estimated before the next set of variables was entered. Variation inflation factor was used to test multicollinearity among explanatory variables. This statistic is smaller than 2 for all variables significant in the final model. Therefore, the multicollinearity is not a concern.

Table 4 presents the hedonic price model for the apartment. The adjusted R-square for the model is 0.740 , indicating a reasonable goodness-of-fit compared to other hedonic models. A comparison of standardized coefficients shows that location and neighborhood attributes of an apartment tend to have a smaller impact on apartment rent than does its structure attributes. 
Table 3: Corrections of Rent with Attributes of the Apartment and Neighborhood

\begin{tabular}{|c|c|c|}
\hline & Correlation & P-value \\
\hline \multicolumn{3}{|l|}{ Objective measures } \\
\hline Accessibility & $-0.199 * *$ & 0.000 \\
\hline Population density & $-0.176^{* *}$ & 0.001 \\
\hline Employment density & 0.031 & 0.545 \\
\hline Retail employment density & -0.027 & 0.601 \\
\hline Service employment density & 0.053 & 0.309 \\
\hline Travel time to the CBD & $0.277 * *$ & 0.000 \\
\hline Living $w /$ in $1 / 8$ mile of bus routes & $-0.249 * *$ & 0.000 \\
\hline Living w/in $1 / 4$ mile of bus routes & $-0.220 * *$ & 0.000 \\
\hline Living w/in $1 / 2$ mile of bus routes & $-0.184 * *$ & 0.000 \\
\hline \multicolumn{3}{|l|}{ Perceived measures } \\
\hline Affordable living unit & $-0.219 * *$ & 0.000 \\
\hline Relatively new living unit & $0.410 * *$ & 0.000 \\
\hline High quality K-12 schools & $0.090 *$ & 0.097 \\
\hline Living on cul-de-sacs & -0.025 & 0.636 \\
\hline Attractive appearance of neighborhood & $0.093 *$ & 0.071 \\
\hline High level of upkeep in neighborhood & $0.135 * *$ & 0.009 \\
\hline Sidewalks throughout the neighborhood & -0.046 & 0.371 \\
\hline Safe neighborhood for kids to play outdoors & 0.071 & 0.177 \\
\hline Easy access to the interstate highway & $0.088^{*}$ & 0.091 \\
\hline Easy access to public transit & $-0.101 *$ & 0.055 \\
\hline Parks and open spaces nearby & 0.028 & 0.589 \\
\hline Local shopping areas within walking distance & -0.021 & 0.679 \\
\hline Easy access to a regional shopping area & 0.071 & 0.168 \\
\hline Close to workplace & $-0.134 * *$ & 0.011 \\
\hline Close to friends or family & $0.112 * *$ & 0.030 \\
\hline Quiet neighborhood & 0.079 & 0.126 \\
\hline Low crime rate within neighborhood & $0.158 * *$ & 0.002 \\
\hline Low level of car traffic on neighborhood streets & 0.050 & 0.335 \\
\hline Economic level of neighbors similar to yours & $0.112 * *$ & 0.033 \\
\hline Ethnicity and race of neighbors similar to yours & 0.020 & 0.702 \\
\hline
\end{tabular}

*significant at the 0.1 level; ** significant at the 0.05 level. 
Table 4: Hedonic Price Model: Linear Regression

\begin{tabular}{lrcc}
\hline & Coeff. & Std. Coeff. & P-value \\
\hline Constant & 268.480 & & 0.000 \\
\# bedrooms & 92.039 & 0.300 & 0.000 \\
\# bathrooms & 67.881 & 0.170 & 0.000 \\
With a patio, balcony, deck or porch & 44.851 & 0.113 & 0.000 \\
Appliances provided in the apartment & & & \\
$\quad$ Microwave & 35.335 & 0.091 & 0.003 \\
$\quad$ Dishwasher & 52.842 & 0.117 & 0.000 \\
$\quad$ Washer/dryer & 78.152 & 0.177 & 0.000 \\
Amenities & & & \\
$\quad$ Clubhouse/community room & 148.095 & 0.362 & 0.000 \\
$\quad$ Swimming pool & 30.006 & 0.058 & 0.053 \\
$\quad$ Landscaped garden & 37.789 & 0.061 & 0.029 \\
$\quad$ Free cable TV/Internet & 57.800 & 0.075 & 0.008 \\
Utilities paid by dwellers & & & \\
Heat & -64.653 & -0.149 & 0.000 \\
\hline Objective measures & & & \\
$\quad$ Living w/in 1/8 mile of bus routes & -23.461 & -0.067 & 0.022 \\
Travel time to the CBD (min.) & -4.906 & -0.092 & 0.004 \\
$\quad$ Retail density & -0.010 & -0.072 & 0.015 \\
Perceived measures & & & \\
$\quad$ Relatively new living unit & 8.997 & 0.056 & 0.078 \\
$\quad$ Living on cul-de-sacs & -19.682 & -0.062 & 0.023 \\
\hline N R-square & 369 & & \\
Adj. R-square & 0.751 & & \\
\hline
\end{tabular}

Not surprisingly, the numbers of bedrooms and bathrooms are positively associated with the lease rate, with the number of bedrooms having a larger impact. Having a patio, balcony, deck, or porch adds about $\$ 46$ to apartment rent, all else equal. Additional appliances provided in the apartment tend to increase the value of apartment. These appliances not only have the value themselves, but also indicate the luxury nature of the apartment. Amenities offered by the apartment complex also have positive impacts on the lease rate. If the dwellers are responsible for heat (heat is expensive in the winter), the rent is reduced by $\$ 63$ on average. A newer apartment also tends to have a higher lease rate.

After controlling for these factors, we found that some measures of accessibility are associated with apartment rent. Interestingly, the model shows that vehicular travel time to CBD has a negative association with the rent. That is, the rent tends to be higher in areas with higher auto accessibility, all else equal. This result is different from their positive association observed in the correlation analysis, and confirms our earlier speculation that auto accessibility may act as a surrogate for other factors. Living on cul-de-sacs has a negative impact on apartment rent. This relationship is reasonable due to the lower accessibility of dead-end streets. It is worth noting that easy access to interstate highway is insignificant in the model, suggesting little location advantage of highway coverage in a small urban area. Apartments located in a TAZ with a higher retail employment density tend to have a lower value than other apartments. This association may result from the noise, traffic, and parking associated with retail businesses. Therefore, although mixed-use neighborhoods can improve the accessibility of residents, an excessive mix may have a negative impact on residential properties. 
The model also shows that on average, apartments located within 1/8 mile of bus routes are $\$ 18.41$ cheaper than other apartments. This suggests that access to bus transit does not increase the value of apartments adjacent to bus routes. Note that if we manually remove living within $1 / 8$ mile of bus routes from the model, neither living within $1 / 4$ mile of bus routes nor living within $1 / 2$ mile of bus routes is significant in the model. This finding suggests that after controlling for other factors, only properties very close to bus routes tend to have a low rent.

\section{DISCUSSION}

Does better access resulting from transit infrastructure increase the value of adjacent properties and buildings? This study explores the impact of bus transit on the lease rate of residential properties in a small urban area. The results showed that vehicular accessibility increases the rent of apartments. In particular, all else equal, vehicular travel time to the CBD (the longer the time, the lower the accessibility) is negatively associated with the rent; apartments on cul-de-sacs (less accessible) tend to have a lower rate than other apartments. However, transit accessibility appears to have a negative impact on the value of apartments. Specifically, after controlling for other factors, apartments located within $1 / 8$ mile of bus routes tend to have a lower lease rate than other apartments.

"Better access means rising market value for adjacent properties and buildings" (APTA undated, p.2). Why does providing bus transit seem to reduce property value in general (e.g., Bina et al. 2006a), and in Fargo in particular? We speculate this observed relationship can be attributed to the two-fold. First, the negative impact of transit infrastructure on apartment rent is the net effect of a positive accessibility effect and a negative nuisance effect. In small urban areas, many people do not appreciate the service of public transportation so that the improved transit accessibility cannot trigger any substantial positive impacts on residential properties. In other words, although bus transit provides an additional travel option, it has a limited ability to improve accessibility of people in small urban areas because historically, they tend to be independent and have little knowledge/ experience on public transit, and hence overwhelmingly rely on private vehicles for their daily activities. This also holds true for apartment dwellers.

Transit itself may have nuisance effects such as noise, crime, and negative image. The noise from rail transits can be a problem (e.g., Chen et al. 1998). However, a bus is not likely to be a major source of noise; at most it is a large vehicle. Transit may also carry negative public perceptions and hence decrease the value of adjacent properties. Transit-related crime is a well-known phenomenon in large metropolitan areas in the U.S. (Loukaitou-Saderis et al. 2002). Public concern over safety and security is one of major reasons that some people live away from transit stations and do not use transit (Ingalls et al. 1993). However, safety is not a major concern in small urban areas, especially in Fargo. Compared to the national average, Fargo has a much lower crime index. And according to the MAT, there is no pattern on transit-related crimes in Fargo although the neighborhood around the Ground Transportation Center (a transfer location), actually downtown Fargo, has a relatively high rate of crime. Negative images of public transportation may matter. There are many web-based debates that transit riders are treated as second-class citizens by other people and even the federal government. These negative images may deter some renters from living close to bus routes and hence decrease the values of adjacent apartments.

Second, proximity to bus routes may act as a proxy for other factors. First, it may be the neighborhoods the transit connects rather than the transit system itself that cause the low lease rate of apartments close to bus routes. One of the fundamental functions of public transit in small urban areas is to provide travel alternatives for transit dependents, and ridership is the centerpiece for initial route design and any further extension of the transit network given budget constraints. Transit agencies tend to prioritize services for neighborhoods accommodating many transit captives who are low-income, disabled, elderly, and/or have no personal vehicles. The availability of transit services may also attract transit captives into such neighborhoods. In Fargo, most bus routes were intentionally designed to connect low-income neighborhoods with workplaces and services. For 
example, many low-income people live in the southwestern corner of 194 and University Drive where a Kmart is located; many elderly people live in the neighborhood around 32nd Avenue North where services are relatively abundant; the bus route along 32nd Avenue South was designed to connect public housing (Figure 2).

Second, the CBD and its weakening role in urban structure may contribute to the negative association. The CBD tends to have a dense transit network. In Fargo, the neighborhood around the east end of the Main Avenue is the traditional center (Figure 2), which was built in the late nineteenth century. Compared to the apartments in outer suburbs, apartments in the CBD tend to have a lower lease rate due to the appearance and functionality of older apartments. Our study confirmed that older apartments tend to have a lower lease rate. Therefore, the impact of bus transit can be a surrogate for the age of apartments. In addition, decentralization can reduce the advantages of a central location and hence lower the value of apartments in the CBD (Giuliano 2004). Because many businesses and services have moved to the regional shopping center around 13th Avenue South mentioned later, downtown Fargo has been losing its attractiveness as a center, and its surrounding areas have gradually become low-income neighborhoods.

Moreover, the low rent of apartments close to bus routes may result from their proximity to commercial districts and busy streets. The agglomeration of businesses has the potential to attract more consumers than a single business. For the convenience of both consumers and employees, transit agencies tend to establish extensive routes in commercial districts. Commercial districts may have nuisance effects such as noise, traffic congestion, and shortage of on-street parking. In Fargo, the northwestern corner of the intersection of I29 and I94 is the regional shopping center where many strip malls and small businesses are clustered. The streets in this area are the busiest, especially during the weekend. And many apartments are located around these commercial districts.

Overall, bus transit seems to have little impact on increasing property value in Fargo, a small urban area. Based on previous research and the information from local authorities, the negative association between transit accessibility and apartment rent is more likely to be a result of spurious relationships: proximity to bus routes is a surrogate for other factors. Although we found that bus transit lacks the potential to increase the value of apartments, this result should not discourage the continuing investments of transit infrastructure. In the data, 7.5\% of apartment dwellers took a bus to grocery stores or shopping malls at least once per month, and $13 \%$ have taken a bus to go shopping. Therefore, transit services in small urban areas play a crucial role in improving the mobility and hence quality of life of a niche market.

\section{Acknowledgements}

The research was funded by the Federal Transit Administration. Julie Bommelman, director of the Fargo Metro Area Transit, and Jim Gilmour, planning director of City of Fargo, provided useful local information. The Advanced Traffic Analysis Center at North Dakota State University offered regional travel demand information. Thanks to Diomo Motuba and Del Peterson for their assistance on calculating land use attributes and drawing the maps. 


\section{References}

American Public Transportation Association (APTA) (undated). The Benefits of Public Transportation: Building Investment in Our Economy and Market. Available at http://www.apta. com/research/info/online/documents/land_use.pdf (accessed July 19, 2007).

Benjamin, J. D. and G.S. Sirmans. "Mass Transportation, Apartment Rent and Property Values.” The Journal of Real Estate Research 12, (1996): 1-8.

Bina, M., V. Warburg and K.M. Kockelman. "Location Choice Vis-à-Vis Transportation: Apartment Dwellers.” Transportation Research Record 1977 (2006a): 93-102.

Bina, M., K.M. Kockelman and D. Suescun. "Location Choice Vis-à-Vis Transportation: The Case of Recent Home Buyers." Presented at the 11th International Association of Travel Behavior Research (IATBR) meeting. Kyoto, Japan. August 16-20 (2006b).

Cao, Xinyu. "Is Alternative Development Undersupplied? An Examination of Residential Preferences and Choices of Northern California Movers." Presented at the 2008 Transportation Research Board Annual meeting, Washington, D.C. (2007).

Cervero, Robert. "Transit-Based Housing in the San Francisco Bay Area: Market Profiles and Rent Premiums." Transportation Quarterly 50 (3), (1996): 33-47.

Chen, H., A. Rufulo and K. Dueker. "Measuring the Impact of Light Rail Systems on SingleFamily Home Values: A Hedonic Approach with Geographic Information System Application." Transportation Research Record 1617, (1998): 38-43.

Chin, T. L. and K.W. Chau. "A Critical Review of Literature on the Hedonic Price Model." International Journal for Housing Science and Its Applications 27, (2003): 145-165.

Gatzlaff, D. H. and M.T. Smith. "The Impact of the Miami Metrorail on the Values of Residences Near Station Locations.” Land Economics 69, (1993): 54-66.

Giuliano, Genevieve. "Land Use Impacts of Transportation Investments: Highway and Transit." S. Hanson and G. Giuliano eds. Geography of Urban Transportation. New York: The Guilford Press (2004): 237-273.

Haider, M. and E.J. Miller. "Effects of Transportation Infrastructure and Location on Residential Real Estate Values: Application of Spatial Autoregressive Techniques." Transportation Research Record 1722, (2000): 1-8.

Ingalls, G.L., D.T. Hargen and T.W. Owen. "Public Fear of Crime and Its Role in Bus Transit Use." Transportation Research Record 1433, (1993): 201-211.

Koutsopoulos, K.C. "The Impact of Mass Transit on Residential Property Values." Annals of the Association of American Geographers 67, (1977): 564-576.

Lewis-Workman, S. and D. Brod. "Measuring the Neighborhood Benefits of Rail Transit Accessibility." Transportation Research Record 1576, (1997): 147-153.

Loukaitou-Saderis, A., R. Liggett and H. Iseki. "The Geography of Transit Crime: Documentation and Evaluation of Crime Incidence On and Around the Green Line Stations in Los Angeles." Journal of Planning Education and Research 22, (2002): 135-151. 
Mackett, R.L. and M. Edwards. "The Impact of New Urban Public Transport Systems: Will the Expectations be Met.” Transportation Research A 32 (4), (1998) 231-245.

Milles, E. and B. Hamilton. Urban Economics, $5^{\text {th }}$ edition. HarperCollins College Publishers, New York, 1994.

Nelson, Arthur C. "Effects of Elevated Heavy-Rail Transit Stations on House Prices with Respect to Neighborhood Incomes.” Transportation Research Record 1359, (1992): 127-132.

Pucher, John. "Public Transportation." S. Hanson and G. Giuliano, eds. Geography of Urban Transportation. New York: The Guilford Press. (2004): 199-236.

Rosen, Sherwin. "Hedonic Prices and Implicit Markets: Product Differentiation in Pure Competition." Journal of Political Economy 82, (1974): 34-55.

Voith, Richard. “Transportation, Sorting, and House Values.” AREUEA 19, (1991): 117-137.

Wegener, M. and F. Fürst. Land-use transport interaction: State of the art. Berichte aus dem Institute für Raumplanung 46, Transland deliverable 2a. Dortmund, Institut für Raumplanung, Universität Dortmund. Available at http://129.3.20.41/eps/urb/papers/0409/0409005.pdf. (1999).

Xinyu (Jason) Cao is an assistant professor of urban and regional planning at the Humphrey Institute of Public Affairs and an affiliate faculty member of department of civil engineering at the University of Minnesota, Twin Cities. His research interests include land use-transportation interactions, environmental correlates of public health, telecommunications and travel behavior, and public transportation.

Jill Hough is director of the Small Urban \& Rural Transit Center within the Upper Great Plains Transportation Institute at North Dakota State University. She is an adjunct professor for agribusiness and applied economics and a professor for the Transportation \& Logistics Ph.D. program at North Dakota State University where she teaches a course in public transportation. Her research interests include public transportation, mobility of the aging, travel behavior, and transportation policy. 